\title{
Two new feather mite species (Acari, Pteronyssidae) from the white-barred piculet, Picumnus cirratus (Aves, Piciformes)
}

\author{
Fabio Akashi Hernandes
}

Departamento de Zoologia, Universidade Estadual Paulista, Av. 24-A, 1515, Rio Claro, SP, 13506-900 Brazil

\begin{abstract}
Two new species of the feather mite family Pteronyssidae Oudemans, 1941 are described from the white-barred piculet, Picumnus cirratus Temminck from Brazil: Pterotrogus picumni sp. n. and Ramphastobius scutatus sp. n., representing the first mites described from this host. Pterotrogus picumni sp. n. can be readily distinguished from all previous species of the simplex group by having dorsal crest on femora I and II in both sexes. This is the first representative of the genus Pterotrogus Gaud, 1981 recorded on a host of the genus Picumnus Temminck. Ramphastobius scutatus sp. n. is unique among species of the genus by having in both sexes the prodorsal and scapular shields fused into a single propodonotal shield covering all prodorsum. An updated key to known species of the genus Ramphastobius Gaud, 1981 is presented.
\end{abstract}

Keywords: new species, Ramphastobius, Pterotrogus, Pteronyssinae, taxonomy, Brazil, Neotropical Region

The white-barred piculet, Picumnus cirratus Temminck (Piciformes, Picidae), is a small woodpecker restricted to the Neotropics. Up to this date, the only record of feather mites associated with birds of the genus Picumnus Temminck was Ramphastobius triangularis Atyeo, Faccini et Gaud, 1987 on Picumnus rufiventris (Bonaparte) (Atyeo et al. 1987), which occurs in the Amazonian rainforest.

The feather mite family Pteronyssidae Oudemans, 1941 was for a long time treated as a subfamily of the Avenzoariidae Oudemans, 1905 (see Gaud and Atyeo 1996). However, Mironov (2001) resurrected the Pteronyssidae based on characters of the ambulacral discs, pretarsus and also host associations of its representatives.

In this paper two new species of pteronyssid mites from the genera Pterotrogus Gaud, 1981 and Ramphastobius Gaud, 1981 are described. An updated key to species of the genus Ramphastobius is also provided.

\section{MATERIALS AND METHODS}

Birds were captured using mist-nets and released after feather examination. Mites were collected from wing feathers and stored in ethanol $(70 \%)$. Acarine specimens were mounted in Hoyer's medium; holotypes and paratypes are deposited in the Collection of Acari of Department of Zoology of Universidade Estadual Paulista, Rio Claro, São Paulo, Brazil (DZUnespRC); paratypes are also deposited in the Institute of Parasitology, Biology Centre ASCR, České Budejovice, Czech Republic (IPCAS). Descriptions of new species are given in the format proposed by Mironov (2005) for the family Pteronyssidae. The nomenclature of idiosomal and leg chaetotaxy follows that of Griffiths et al. (1990) and Atyeo and Gaud (1966), respectively.
Measurements are given in micrometres; measurements were taken as follows: idiosoma length from the anterior end of prodorsal shield to lobar apices (excluding terminal appendages in females); the greatest idiosoma width was measured at the widest portion at the level of humeral shields; distance between setae of the same pair was taken as the direct distance between their bases, and distance between different pairs is the direct distance formed by their bases at the same side of the body; dorsal shield length was measured as the greatest length from anterior margin to posterior end along the midline and width is the greatest width at the widest part of posterior margins. Scientific names of birds follow Dickinson (2003).

\section{RESULTS}

Pterotrogus picumni sp. n.

Figs. 1-3

Male (holotype). Length of idiosoma 266, greatest width of idiosoma 136 (idiosomal size in five paratypes 253-266 × 131-146). All dorsal shields fused into single idiosomal shield; traces of fusion between prodorsal and scapular shields visible (Fig. 1A), surface without ornamentation, lateral margins of prodorsal area of this shield with small incisions encircling scapular setae se, which appear inserted off shield, distance between setae se 85; setae $s i$ inserted on prodorsal shield, approximately in same longitudinal level of setae $c 1$. Length of hysterosoma from level of setae $c 2$ to lobar apices 165. Setae $c 3$ lanceolate, 19 in length. Dorsal setae $e 1$ situated anterior to level of lateral setae $e 2$, bases of these setae arranged in trapezium; hysteronotal gland openings $g l$ poorly developed, set approximately at midway between setae $e 1$ 


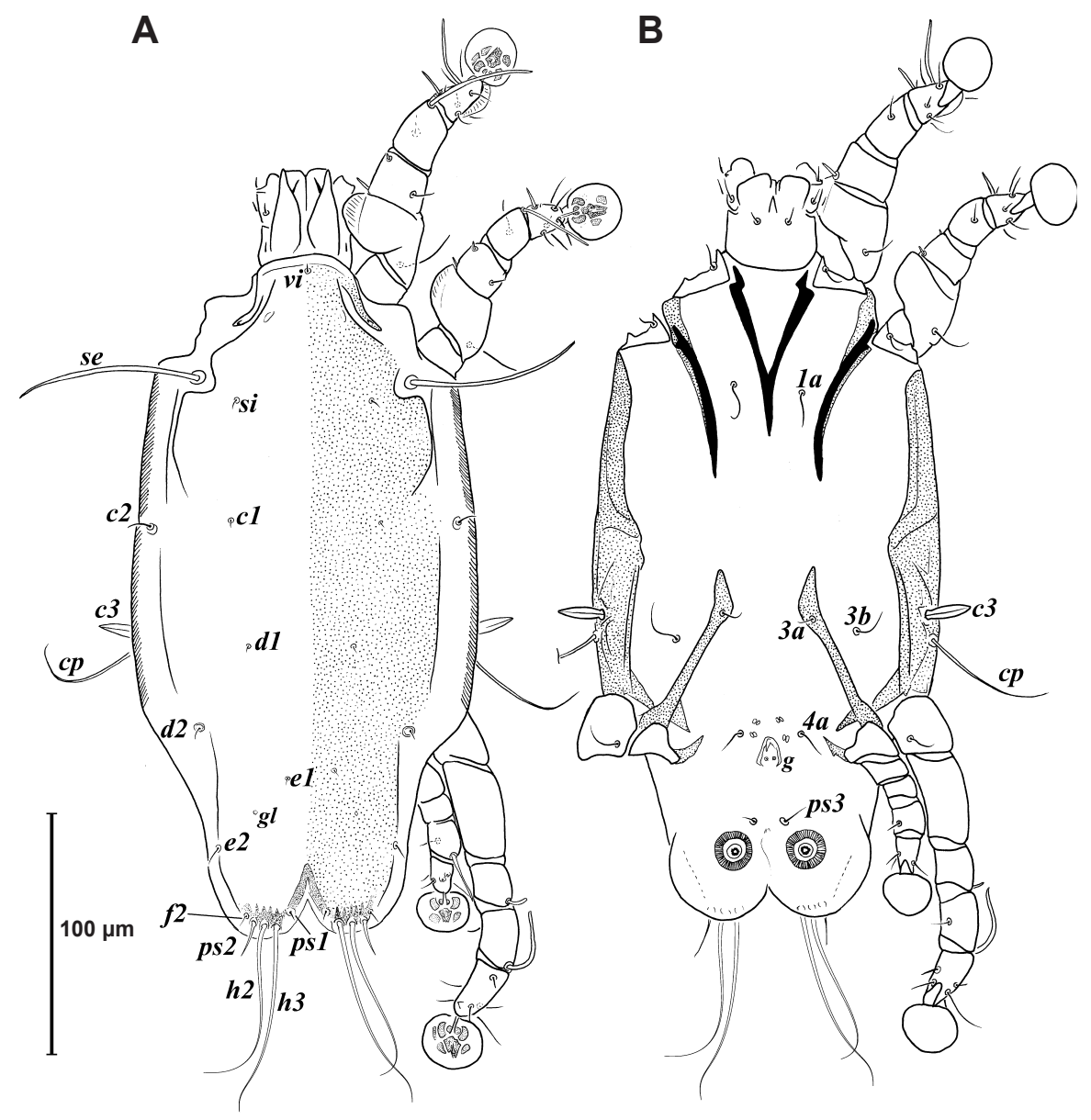

Fig. 1. Pterotrogus picumni sp. n., male: dorsal (A) and ventral (B) views.

and $e 2$ and arranged with these setae into a straight line. Setae $p s 1$ setiform, 7 in length. Opisthosoma wide, about half greatest body width, with short and widely rounded opisthosomal lobes; terminal cleft with acute anterior end, 23 in length. Dorsal measurements: $c 2-d 283, d 2-e 249$, d2-gl 20, gl-el 19, e2-el 39, e2-h3 42, h2-h2 34, h3-h3 25, ps1-ps1 17, ps2-ps 243 . Epiandrium absent. Setae $3 a$ slightly anterior to $3 b$, situated on sclerotized inner ends of epimerites IIIa (Fig. 1B). Genital arch 14 in length, 11 in width, aedeagus half as long as arch length, coxal setae $4 a$ inserted slightly anterior to level of genital arch. Adanal apodemes, adanal shields and adanal membranes absent. Femur I and II with dorsal crest, tarsus I with ventral membrane. Tarsus III with apical claw, 21 in length. Tarsus IV without dorsobasal teeth; modified seta $d$ and $e$ spine-shaped, weakly sclerotized (Fig. 3D).

Female (allotype). Length of idiosoma 417, width of idiosoma 164 (idiosomal size of one additional paratype $430 \times 202$ ). Prodorsal and hysteronotal shields fused into a large dorsal shield; scapular and humeral shields fused (Fig. 2A), setae se separated by 97; setae $s i$ situated on prodorsal shield, close to acute incisions next to setae se. Length of hysterosoma from level of setae $c 2$ to posterior end 297. Setae $c 3$ lanceolate, 23 in length.
Posterior margin of opisthosoma rounded, median area near posterior margin more sclerotized than remaining area, anterior border of this sclerotized patch straight or slightly concave. Setae $d 1$ slightly below the level of humeral setae $c p$, setae $e 1, e 2$ and gland opening arranged in straight line as in the male. Setae $p s 1$ short setiform, 6 in length. External copulatory tube as small weakly sclerotized terminal extension, 6 in length. Dorsal measurements: $c 2-d 2121, d 2-e 2$ 107, e2-f2 60, e2-e1 56, h2-h2 51, ps 1-ps1 32.

Epigynium a long arch, 64 in length, 64 in width, with acute anterolateral extensions; sclerotized fold of oviporus long, extending to midlevel of epimerites IV (Fig. 2B). Head of spermatheca as in Fig. 2C.

Ty p e host: Picumnus cirratus Temminck (Picidae)

Type 1ocality: São José dos Campos, São Paulo State,

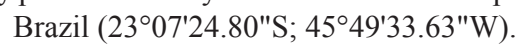

Type materia 1: Holotype (male) from a male of the whitebarred piculet Picumnus cirratus, 08. vi.2011, collected by A.M. Montanhini; paratypes: 7 males, 2 females, same data as the holotype. Coll. No: DZUnesp-RC from 00008 to 00016, IPCAS 2034.

E ty mology: The specific name is derived from the genus of the type host as a noun in the genitive case. 


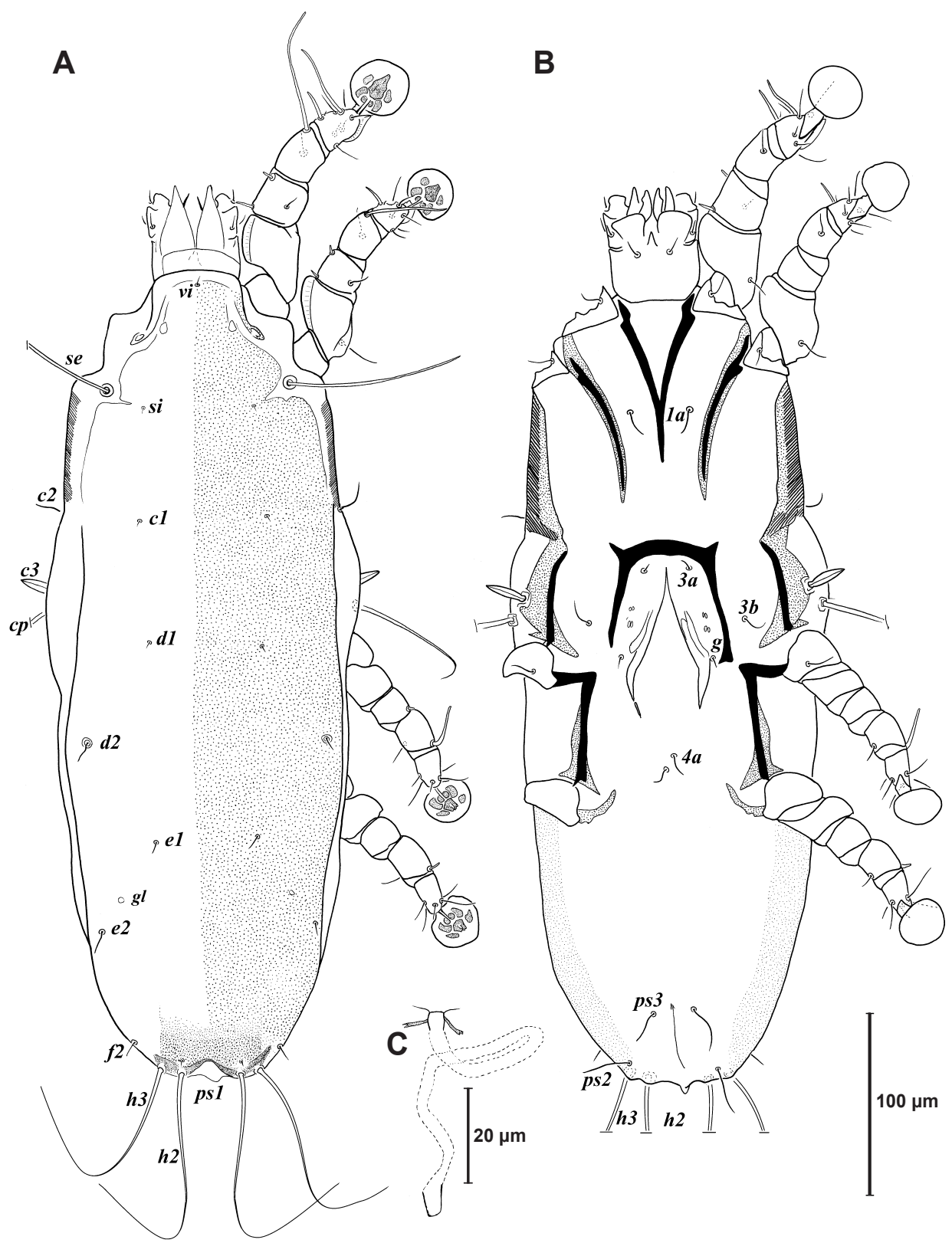

Fig. 2. Pterotrogus picumni sp. n., female: dorsal (A) and ventral (B) views, spermatheca (C).

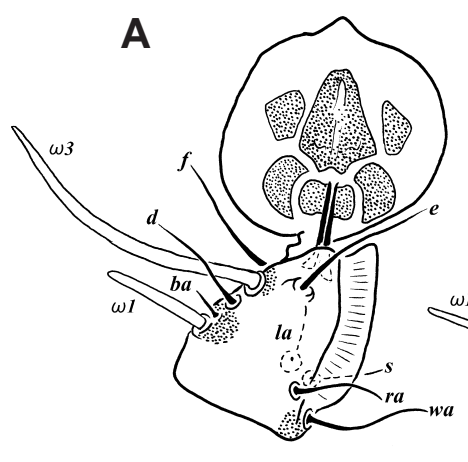

B
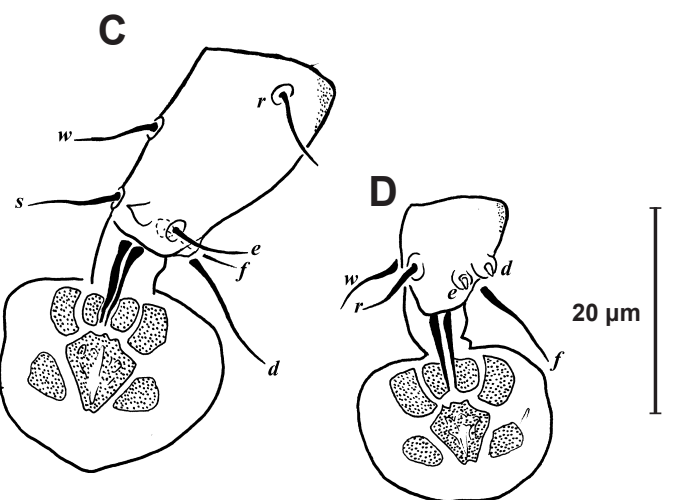

Fig. 3. Pterotrogus picumni sp. n., male: tarsi I to IV (A-D). 


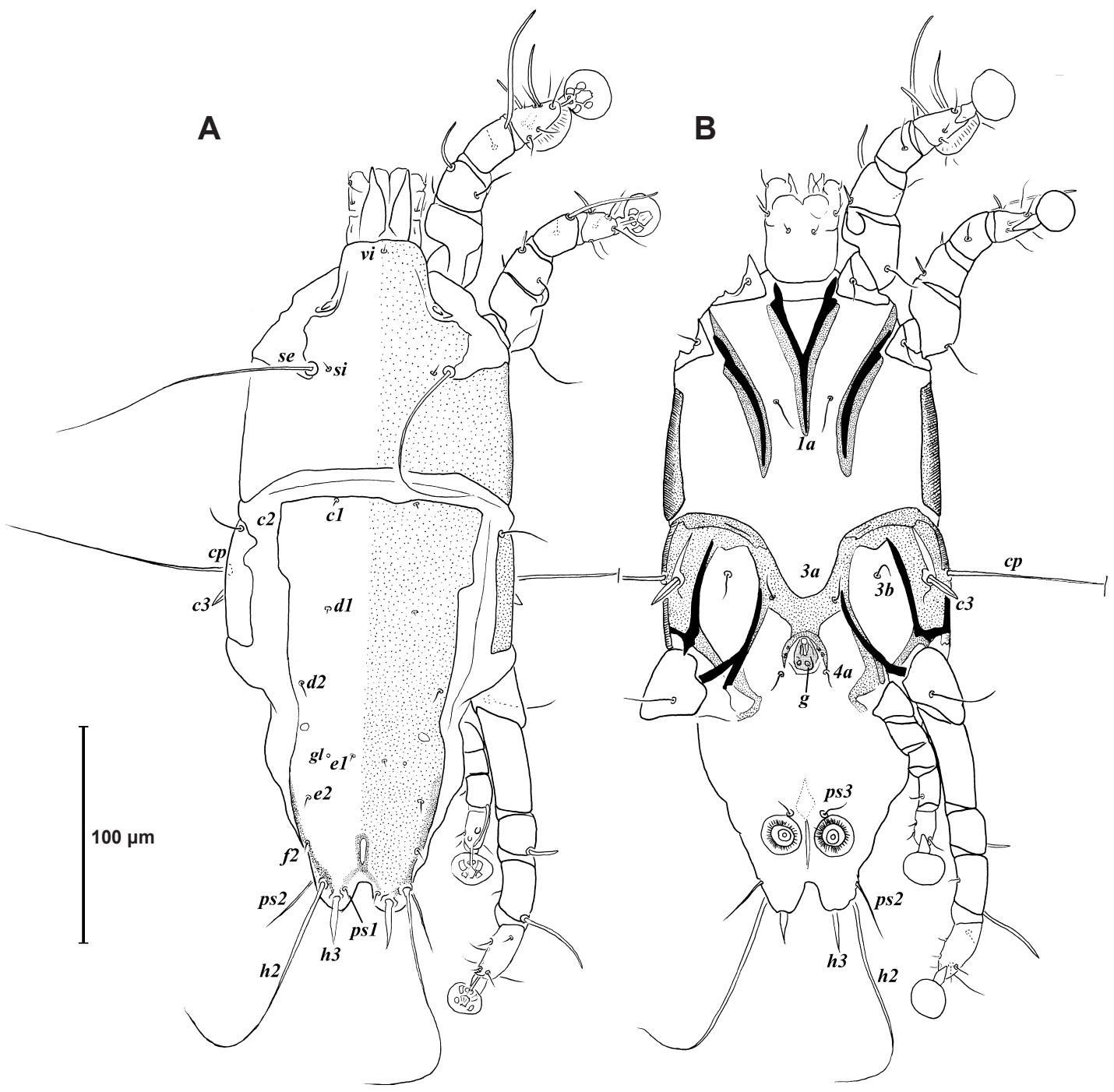

Fig. 4. Ramphastobius scutatus sp. n., male: dorsal (A) and ventral (B) views.

Differential diagnosis. The new species belongs to the simplex group by having setiform setae on the terminal region of the opisthosoma. It most closely resembles $P$. colapti Mironov, 2005 by having in both sexes prodorsal setae $s i$ on the dorsal shield (rather than in incisions formed by lateral margins of this shield). It can be distinguished from that species by having dorsal crest on femora I and II in both sexes, setae $e 2$ almost on the lateral margins of the dorsal shield in males, and by the setae $e 1, e 2$ and gland openings arranged in a straight line in both sexes (Figs. 1A, 2A). In $P$. colapti the setae $e 2$ are inserted noticeably at midlength from the lateral margins of hysteronotal shield, crests on femora are absent, and bases of setae $e 1$, $e 2$ and gland openings are arranged in a triangle.

Remarks. Feather mites of the genus Pterotrogus are characterized by having the prodorsal and hysteronotal shields completely fused into a large and single dorsal shield. The genus currently includes 16 species arranged in four species groups (iron, lanceolatus, simplex and sinusoidus) and is known exclusively from woodpeck- ers (Piciformes, Picidae) in the Americas (Mironov 2005, Mironov et al. 2005).

\section{Ramphastobius scutatus sp. n.}

Figs. 4-6

Male (holotype). Length of idiosoma 316, greatest width of idiosoma 127 (idiosomal size of two paratypes 319-331 × 142-150). Prodorsal and scapular shields fused into a single propodosomal shield (Fig. 4A), surface without ornamentation, lateral margins of this shield with incisions extending to setae se, greatest length of shield 65, distance between setae se 65. Propodosomal and hysteronotal shields separated by transverse band of soft tegument. Setae $c 1$ on anterior margins of hysteronotal shield, setae $c 2$ on the anterolateral margins of humeral shields. A pair of circular areas (cupules $\mathrm{im}$ ) situated near lateral margins of hysteronotal shield, between setae $d 2$ and $e 2$. Length of hysterosonotal shield from level of setae $c 1$ to lobar apices 193, width at anterior margin 96-99. Setae c3 lanceolate, 19 in length. Hysteronotal gland 


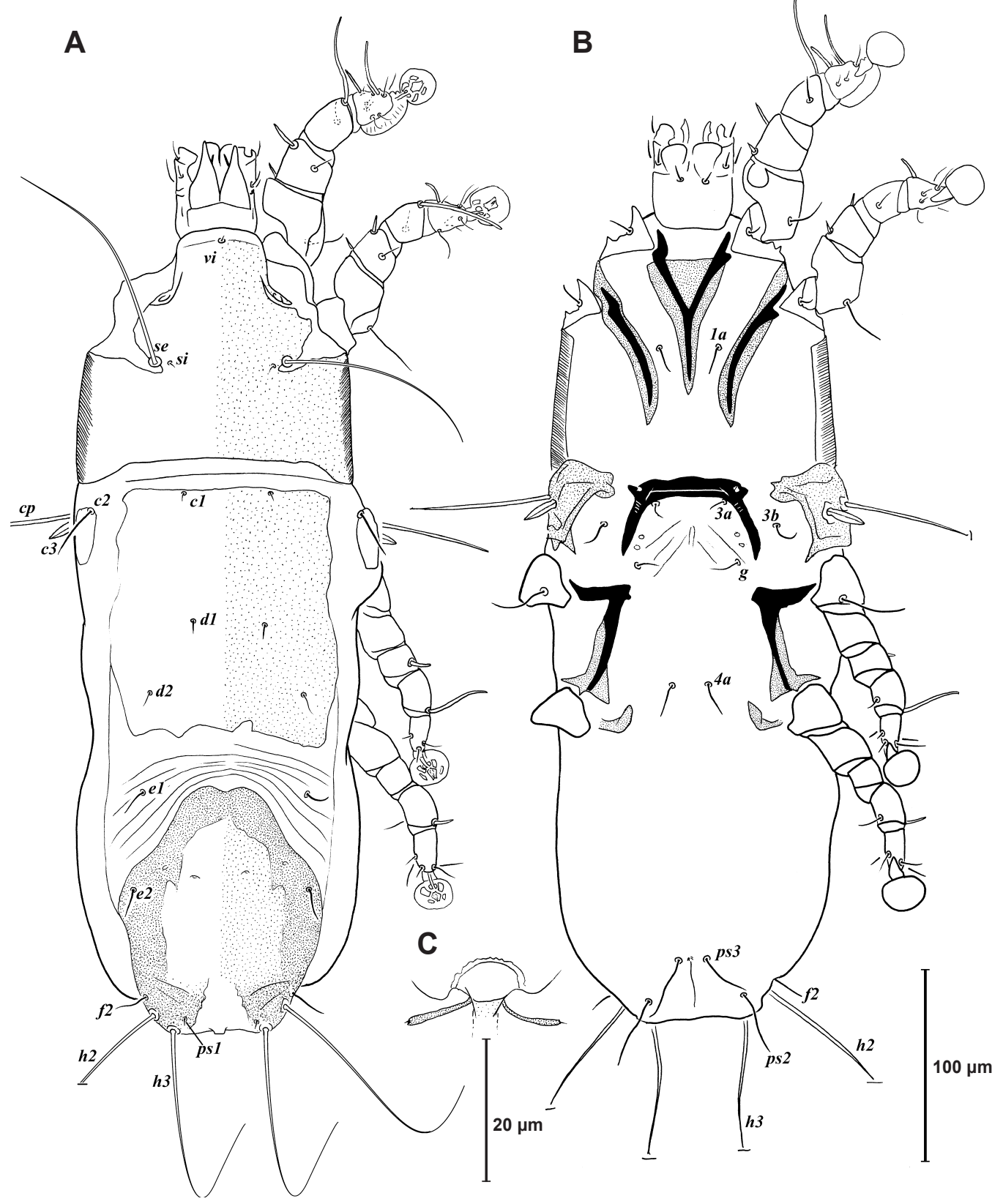

Fig. 5. Ramphastobius scutatus sp. n., female: dorsal (A) and ventral (B) views, spermatheca (C).

openings $g l$ poorly developed, at level of setae $e 1$, setae ps 1 setiform, 12 in length. Opisthosomal lobes rounded; terminal cleft shaped as a rounded trapezium, 15 in length. Dorsal measurements: $c 2-d 275, d 2-e 253, e 2-e 1$ 28, e2-h3 50, h2-h2 35, h3-h3 25, ps1-ps1 17, ps2-ps2 43. Genital papillae situated on epiandrium. Setae $3 a$ situated on transventral sclerite (Fig. 4B). Genital arch 19 in length, 12 in width, aedeagus half as long as arch length. Adanal apodemes, adanal shields, and adanal membranes absent. Tarsus III with apical claw, 35 in length. Tarsus IV without dorsobasal teeth; modified seta $d$ and $e$ buttonlike (Fig. 6D).

Female (allotype) (range for six paratypes in parentheses). Length of idiosoma 426 (420-434), width of idiosoma 158 (159-188). Prodorsum covered with entire shield as in male (Fig. 5A), setae se separated by 71 (7075). Setae $c 2$ inserted on anterolateral margins of humeral shield. Prodorsal shield length along midline 121 (116123), distance between prodorsal and anterior hysteronotal shields 16 (14-21). Hysteronotal shield divided into anterior and posterior parts; anterior hysteronotal shield bearing setae $c 1, d 1$ and $d 2$, length along midline 128 (125-134), width at anterior margins 110 (108-112); setae $e 1$ situated on the striated tegument; posterior hysteronotal shield length along midline 132 (128-138), width at level of setae e2 104 (102-105). Length of hysterosoma from level of setae $c 2$ to posterior end 281 (278-291). Setae $c 3$ lanceolate, 21 (19-20) in length. Posterior margin 

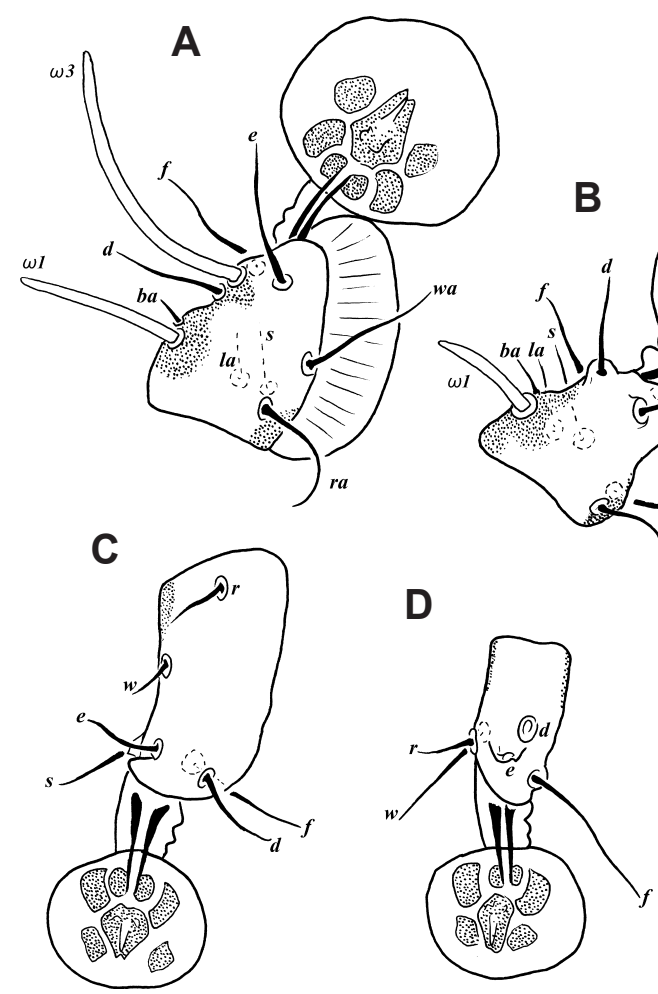

Fig. 6. Ramphastobius scutatus sp. n. male: tarsi I to IV (A-D).

of opisthosoma straight, without lobes; setae ps 1 short, setiform, about 5 in length. External copulatory tube as small weakly sclerotized terminal extension, 5 in length. Dorsal measurements: $c 2-d 299$ (98-105), d2-e2 106 (99-107), h2-h2 69 (63-76), ps1-ps1 39 (34-40). Epigynium 41 (39-40) in length, 68 (70-73) in width, with short anterolateral extension. Head of spermatheca as in Fig. 5C.

Type host: Picumnus cirratus Temminck (Picidae).

Type locality: São José dos Campos, São Paulo State, Brazil (2307'24.80"S; 4549'33.63"W).

Type materia 1: Holotype (male) from a male of the whitebarred piculet Picumnus cirratus, São José dos Campos, São Paulo State, Brazil (band F14750), 08. vi. 2011, collected by A.M. Montanhini; paratypes: two males, seven females, same data as the holotype. Coll. no.: DZUnesp-RC from 00001 to 00007 , IPCAS 2031.

Etymology: The specific name refers to the unique feature of the prodorsal and scapular shields fused into a large propodosomal shield, and is a noun in apposition.

Differential diagnosis. The new species most closely resembles $R$. triangularis Atyeo, Faccini et Gaud, 1987 by having in both sexes setae $c l$ inserted on the anterior margins of hysteronotal shield and the prodorsal shield without ornamentation. It can be readily distinguished from the latter and from all previously described species of the genus by having in both sexes the prodorsal and scapular shields fused into a single propodonotal shield covering all prodorsum.
Remarks. The genus Ramphastobius is characterized by having setae $h 3$ blade-like and coxal fields III closed in males, and by the conspicuous ventral membranes on tarsi I in both sexes. The genus currently comprises 12 species including the new species described herein; its representatives have been recorded from birds of three families of the order Piciformes: Ramphastidae, Capitonidae and Picidae (Picumninae only), from the Neotropical region (Trouessart 1885, Černý 1975, Faccini and Atyeo 1981, Atyeo et al. 1987).

\section{Key to species of Ramphastobius Gaud 1987}

(modified from Atyeo et al. 1987); males and females

1. Setae $c 1$ inserted on striated tegument between prodorsal and hysteronotal shields

- Setae $c 1$ inserted on anterior margins of hysteronotal shield 5

2. Prodorsal and hysteronotal shields close together, separated by narrow band of striated tegument, this area about half the distance between setae $s i$

R. chiasma (Trouessart, 1885)

- Prodorsal and hysteronotal shields broadly separated by transverse band of striated tegument, length of this area approximately the same as distance between setae $s i$

3. Posterior margin of prodorsal shield nearly straight, with lateral incisions posterior to bases of setae se, width at posterior margins of this shield wider than distance between setae se.

R. senticosus Atyeo, Faccini et Gaud, 1987

- Posterior margin of prodorsal shield convex, without incisions posterior to setae se, width at posterior margins of this shield equal to or less than distance between setae se 4

4. Setae $h 3$ in males lanceolate; hysteronotal shield in females divided into anterior (bearing setae $d 1$ and $d 2$ ) and posterior (bearing setae $e 1$ and $e 2$ ) parts

R. mucronatus (Trouessart, 1885)

- Setae $h 3$ in males setiform; hysteronotal shield in females entire

R. cinctutus Atyeo, Faccini et Gaud, 1987

5. Prodorsal and scapular shields fused into a large shield occupying entire prodorsum .... R. scutatus sp. n.

- Prodorsal and scapular shield not fused 6

6. Posterior margins of prodorsal shield in males straight, posterolateral angles without acute extensions; female hysteronotal shield split into anterior and posterior pieces 7

- Posterior margins of prodorsal shield in males convex, its posterolateral angles with acute extensions; female hysteronotal shield entire 8 
7. Central area of prodorsal shield ornamented in both sexes; in females, setae $d 2$ situated on the anterior hysteronotal shield

R. loricatus Atyeo, Faccini et Gaud, 1987

- Prodorsal shield in males without ornamentation; in females, setae $d 2$ situated on striated tegument between anterior and posterior hysteronotal shields

R. triangularis Atyeo, Faccini et Gaud, 1987

8. In both sexes, central area of prodorsal shield with circular/ovoid ornamentation resembling the Egyptian symbol ankh (q)

- Central area of prodorsal shield without ornamentation 10

9. Posterolateral angles of prodorsal shield with acute extentions; ovoid medial lacunae on anterior portion of this shield large, occupying nearly entire area between setae $v i$ and scapular setae se and $s i$

R. callinoticus Atyeo, Faccini et Gaud, 1987

- Posterolateral margins of prodorsal shield rounded, without extentions; ovoid lacunae on anterior portion of prodorsal shield small, occupying approximately $1 / 3$ of the area between setae $v i$ and scapular setae se and $s i$ R. hyalifer (Černý, 1975)

10. Hysteronotal shield with transverse row of circular lacunae between setae $c l$ and $d l$ 11

- Hysteronotal shield without lacunae between setae $c 1$ and $d 1$....... R. minimus Atyeo, Faccini et Gaud, 1987
11. Posterior margin of prodorsal shield convex, this shield ending at level slightly posterior to scapular setae $s e$ and $s i$ R. bifidus (Trouessart, 1885)

- Posterior margin of prodorsal shield straight, with at least $1 / 3$ of this shield below to level of scapular setae se and si .... R. dubinini Atyeo, Faccini et Gaud, 1987

\section{DISCUSSION}

Valim et al. (2011) estimated that the diversity of feather mite fauna in Brazil, which harbours one of the most diverse bird fauna of the world ( $c$ a 1800 bird species, CBRO 2011). According to those authors, a bird species would normally host 2-3 feather mite species on average, and in some extreme cases can host more than 25 feather mite species, like the green parakeet, Arating a holochlora (Sclater) (Pérez 1997). Here the first feather mite species associated with the white-barred piculet are described. The genus Pterotrogus, previously known from woodpeckers of the genera Campephilus Gray, Colaptes Vigors, Dryocopus Boie, Picoides Laépède, and Veniliornis Bonaparte, is for the first time found on a host from the genus Picumnus.

Acknowledgements. Thanks are due to Arthur Macarrão Montanhini for collecting the mites from the white-barred piculet, to Sergey V. Mironov, for critical reading of the manuscript and valuable comments and also to two anonymous reviewers for valuable comments and suggestions. This study was supported by the FAPESP - São Paulo Research Foundation (2011/50145-0, 2011/20805-8).

\section{REFERENCES}

Atyeo W.T., Faccini J.L.H, Gaud J. 1987: The feather mite genus Ramphastobius Gaud (Avenzoariidae) associated with neotropical Piciformes (Aves). Parazit. Sb. 34: 150-168.

Atyeo W.T., Gaud J. 1966: The chaetotaxy of sarcoptiform feather mites (Acarina: Analgoidea). J. Kansas Entomol. Soc. 39: 337-346.

CBRO 2011: Checklist of the Brazilian Committee of Ornithological Records [Internet]. Available from: http://www.cbro.org.br/ $\mathrm{CBRO} / \mathrm{pdf} /$ AvesBrasil2011.pdf.

Černý V. 1975: Parasitic mites of Surinam XXXII. New species of feather mites (Sarcoptiformes, Analgoidea). Folia Parasitol. 22: $233-240$

Dickinson E.C. (Ed.) 2003: The Howard and Moore Complete Checklist of the Birds of the World. 3rd ed., Princeton University Press, New Jersey, $1039 \mathrm{pp}$.

Faccini J.L.H., Atyeo W.T. 1981: Generic revisions of the Pteronyssinae and Hyonyssinae (Analgoidea: Avenzoariidae). Proc. Acad. Nat. Sci. Philadelphia 133: 20-72.

Gaud J., Atyeo W.T. 1996: Feather mites of the world (Acarina, Astigmata): the supraspecific taxa. Ann. Mus. R. Afr. Centr. Sci. Zool. 277 (1): 1-187, (2): 1-436.

Griffiths D.A., Atyeo W.T., Norton R.A., Lynch C.A. 1990: The idiosomal chaetotaxy of astigmatid mites. J. Zool. 220: $1-32$.
Mironov S.V. 2001: Description of four new genera of the feather mite family Pteronyssidae Oudemans, 1941 (Astigmata: Analgoidea) with notes on systematics of the family. Acarina 9: $3-22$.

Mironov S.V. 2005: Feather mites of the genus Pterotrogus Gaud 1981 (Analgoidea: Pteronyssidae) from the New World woodpeckers (Piciformes: Picidae). Belg. J. Zool. 7: 129-180.

Mironov S.V., Dabert J., Ehrnsberger R. 2005: A new species of the feather mite genus Pterotrogus Gaud (Analgoidea: Pteronyssidae) from the ivory-billed woodpecker Campephilus principalis L. (Aves: Piciformes). Ann. Entomol. Soc. Am. 98: $13-17$.

Pérez T.M. 1997: Eggs of feather mite congeners (Acarina: Pterolichidae, Xolalgidae) from different species of New World parrots (Aves, Psittaciformes). Int. J. Acarol. 23: 103-106.

Trouessart E.L. 1885: Note sur la classification des Analgésiens et diagnoses d'espèces et de genres nouveaux. Bull. Soc. Etud. Sci. Angers 14: 46-89.

Valim M.P., Hernandes F.A., Proctor H.C. 2011: Feather mites of Brazil (Acari: Astigmata: Analgoidea and Pterolichoidea). Int. J. Acarol. 37: 293-324.

Accepted 9 August 2012 